\title{
The implications of labour unions in the presence of a merger*
}

\author{
Jiyun Cao \\ The School of Economics, Nankai University, Tianjin, China, \\ and Collaborative Innovation Center for China Economy, Tianjin, China

\begin{abstract}
Arijit Mukherjee
Nottingham University Business School, UK, CESifo, Germany, INFER, Germany and GRU, City University of Hong Kong, Hong Kong
\end{abstract} \\ and \\ Uday Bhanu Sinha \\ Delhi School of Economics, India
}

Submission: June 2018

Revised version: September 2019

Accepted: October 25, 2019

\begin{abstract}
It is usually believed that the presence of labour unions is detrimental for the consumers since it raises wage. We show that this view may not be true if we endogenise the impacts of labour unions on firms' corporate strategies such as merger and acquisition. The presence of labour unions may benefit the consumers by deterring merger.
\end{abstract}

Key words: Labour union; Bertrand competition; Cournot competition; Consumer surplus; Merger

JEL Classifications: D43; J51; L12; L13

Correspondence to: Arijit Mukherjee, Nottingham University Business School, Jubilee Campus, Wollaton Road, Nottingham, NG8 1BB, UK. Email: arijit.mukherjee@nottingham.ac.uk; Fax: +44 (0)115 8466667

\footnotetext{
* We would like to thank two anonymous referees of this journal for helpful comments and suggestions. Jiyun Cao acknowledges the support from the Fundamental Research Funds for the Central Universities (Project Code: 63192903). The usual disclaimer applies.
} 


\section{The implications of labour unions in the presence of a merger}

\section{Introduction}

It is generally believed that the presence of labour unions raises wage and makes the consumers worse off compared to a competitive labour market (Hirsch, 1997 and Shrek, 2009). While this argument is intuitive, it ignores the impacts of labour unions on firms' corporate strategies such as merger and acquisition, which has a significant effect on the market structure and is empirically relevant. ${ }^{1}$ We show that if we internalise the effects of labour unions on firms' decision on merger and acquisition, the abovementioned result may not hold true.

More specifically, we do the following analysis. We consider a duopoly market structure and show when merger, creating synergic benefit, is privately and socially beneficial. In the absence of labour unions, it is always privately beneficial but it is also socially beneficial if the synergic benefit is sufficiently large. We then find out the conditions under which the presence of labour unions deters such merger. We show that labour unions make the merger privately unprofitable or will not be allowed by the policymaker if the synergic benefit is not very large. Comparing consumer surplus under "union and no merger" to that of under "no union and socially beneficial merger", we find that the consumer surplus may be higher under the former situation, and it holds under both Cournot and Bertrand competition in the product market. Our result suggests

\footnotetext{
1 The empirical work by Fallick and Hassett (1996) investigated the influence of labour unions on merger.

2 We focus on socially beneficial merger, since the merger will not be allowed by the policymaker if it is not socially beneficial. Hence, our problem is important provided merger is socially beneficial. We thank the referees for highlighting this point.
} 
that the literature might have overestimated the adverse effects of labour unions on the consumers.

The mechanism behind our result, i.e., the presence of labour union reduces the incentive for merger compared to competitive labour market (or no labour union), may get support from the merger data shown in Fallick and Hassett (1996). In their 1977-79 sample, the number of non-union acquirer-target pair is 43 but the number of union acquirer-target pair is 36 . In their 1982-85 sample, the number of non-union acquirertarget pair is 160 but the number of union acquirer-target pair is 26 .

To the best of our knowledge, there are only two other papers by Mukherjee and Wang (2013) and Cao and Mukherjee (2017) showing the favourable effects of labour unions on the consumers. However, in contrast to our emphasis on the labour union's impact on a merger, Mukherjee and Wang (2013) showed the labour union's effect on entry of a technologically superior firm while Cao and Mukherjee (2017) paid attention to the labour union's effect on technology licensing.

Our paper is closely related to the literature on the pro-competitive effects of labour unions (Straume, 2002 and Lommerud et al., 2005). In an international duopoly supergame, Straume (2002) showed that the presence of labour unions can have procompetitive effect leading to intra-industry trade as opposed to autarky where the firms from different countries collude and avoid selling in each other's market. Because intraindustry trade creates product market competition, the firms have the incentive to collude to autarky and not to engage in intra-industry trade in the absence of labour unions. However, the presence of unions may change the firms' incentive to collude to 
autarky. By creating competition among the firms, the intra-industry trade helps to reduce the unions' power to extract rent from the firms through higher wages compared to autarky, which induces the firms to engage in intra-industry trade. This procompetitive effect of unions may create higher welfare under union compared to no union. In contrast, we show the beneficial effects of labour unions on the consumers in a closed economy with differentiated goods, firm-specific unions where the merger of the firms also entails merger of the labour unions, and in a one-shot game.

The paper closest to ours is Lommerud et al. (2005) which showed the effects of labour unions on merger under Cournot competition with differentiated products. They show that if the unions are plant-specific, the presence of unions increases the incentive for a merger compared to competitive labour markets. However, the opposite happens if the unions are firm-specific. Hence, like us, they also show that the presence of firmspecific unions reduces the incentive for merger. However, unlike us, they didn't consider the effects of unions on the consumers. We show how the labour unions can benefit the consumers by creating the pro-competitive effect by preventing merger. In doing so, we focus on those mergers which will be allowed by the policymaker. ${ }^{3}$

Like Kao and Menezes (2010), we focus on those privately profitable mergers which will be allowed by the policymaker due to their positive effects on total surplus. However, our focus is different from theirs. While they show the welfare effects of mergers under Cournot and Bertrand competition, we show the effects of labour unions

\footnotetext{
3 There are some other papers considering merger in the presence of labour unions (see, e.g., Straume, 2003, Lommerud et al., 2006, Symmeonidis, 2008, 2010 and Mukherjee, 2010). However, unlike our paper, these papers are not considering the effects of unionised labour markets (compared to competitive labour markets) on the consumers.
} 
on the consumers in the presence of a merger.

The remainder of the paper is organised as follows. Section 2 describes the model and derives the results. Section 3 concludes.

\section{The model and the results}

Consider two firms, firms 1 and 2, producing differentiated goods. The preference of the representative consumer is given by $U_{c}\left(q_{1}, q_{2}\right)=a\left(q_{1}+q_{2}\right)-\frac{q_{1}^{2}+q_{2}^{2}}{2}-\gamma q_{1} q_{2}$, where $q_{1}$ and $q_{2}$ denote the outputs of firms 1 and 2 respectively under no merger, or denote the outputs of two differentiated goods of the merged firm, firm $\mathrm{M}, \mathrm{a}>0$, and $\gamma(0<\gamma<1)$ denotes the degree of product differentiation. We ignore two extreme cases of isolated goods $(\gamma=0)$ and perfect substitutes $(\gamma=1)$ to ignore lack of competition among the products and "Bertrand paradox" in the product market. Thus, the inverse demand functions for two goods are respectively

$$
P_{1}=a-q_{1}-\gamma q_{2} \text { and } P_{2}=a-q_{2}-\gamma q_{1}
$$

The respective direct demand functions for two goods are

$$
q_{1}=\frac{(1-\gamma) a-P_{1}+\gamma P_{2}}{1-\gamma^{2}} \text { and } q_{2}=\frac{(1-\gamma) a-P_{2}+\gamma P_{1}}{1-\gamma^{2}} .
$$

Hence, the consumer surplus is $C S=U_{c}\left(q_{1}, q_{2}\right)-P_{1} q_{1}-P_{2} q_{2}=\frac{q_{1}^{2}+q_{2}^{2}}{2}+\gamma q_{1} q_{2}$.

Labour is assumed to be the sole input used in the following way. Since our purpose is to show the implications of labour unions, we will consider two kinds of labour market: (i) a competitive labour market with a constant wage $c$ per unit of labour employed by any firm, and (ii), firm-specific labour unions determining the wages for the respective firms (see, e.g., Straume, 2003, López and Naylor, 2004, Lommerud et 
al., 2005 and Symeonidis, 2010).

To show the maximum effects of labour unions in contrast to a competitive labour market, we assume that the labour union has full bargaining power. Further, like the papers with labour unions mentioned in the introduction, we consider a right-to-manage model of labour union, where the unions determine wages and the firms hire workers according to their needs. Specifically, the ith union, $i=1,2$, M, chooses wage, $w_{i}$, to maximise its utility $U_{i}=\left(w_{i}-c\right)^{2 \alpha} L_{i}^{2(1-\alpha)}$, where $L_{i}$ is employment in the $i$ th firm, the subscripts 1,2 and $M$ are for firm 1, firm 2 and the merged firm respectively, and $\alpha$ (resp. $1-\alpha$ ) shows the labour union's preference for wage (resp. employment), with $0<\alpha<1$.

If the firms compete non-cooperatively, we assume that one unit of labour is required to produce one unit of the output in each firm. This implies $L_{1}=q_{1}$ and $L_{2}=q_{2}$ under no merger. If firms 1 and 2 merge, we assume that the merger gives rise to a synergic benefit (see, e.g., Davidson and Mukherjee, 2007) and allows the merged firm to produce each unit of both brands by using $\beta(0<\beta<1)$ units of labour. This indicates $L_{M}=\beta\left(q_{1}+q_{2}\right)$ under merger.

Since we consider firm specific unions, there will be a single firm-specific union under merger. Hence, the union specific to the merged firm sets the wage and the firm decides on the level of employment to produce two different brands of the product. In other words, the two unions merge as a consequence of the merger. Firm-specific unions can be found also in Lommerud et al. (2005) and Mukherjee and Zhao (2016). This can be justified following Lommerud et al. (2005). If the unions are plant-specific, a merger 
may reduce rent extraction by the unions, which induces the unions to create a single firm-specific union. The unions might have the incentive to coordinate even when the firms behave non-cooperatively. However, cooperation between the unions will not be sustainable (in a one shot game considered in the paper or for a finite horizon game) under non-cooperation, due to each union's incentive for unilateral deviation from cooperation, but merger between the firms give the unions the opportunity to coordinate credibly. For empirical evidence showing the causal link between corporate and labour union mergers, one may look at Buchanan (1974, 1981), Chitayat (1979) and Geroski and Knight (1984).

We consider the following game. At stage 1, the firms decide on merger, which the policymaker decides whether to permit. If the profit of the merged firm is higher than their total profits under no merger, the firms would like to merge if allowed by the policymaker. However, the policymaker will allow the merger if it increases the total surplus ${ }^{4}$. At stage 2, if there are labour unions, the wages are determined by the unions. If the labour market is competitive, the equilibrium wage is $c$. At stage 3, firms choose the level of employment and compete in the product market by choosing either outputs or prices, and the profits are realized. We solve the game through backward induction.

\footnotetext{
${ }^{4}$ We consider total surplus instead of social welfare because it is intuitive that sufficiently higher weight on the union's utility will create higher welfare in the presence of labour unions compared to a competitive labour market, since the wage premium under a competitive labour market is zero.
} 


\subsection{No labour union}

\subsubsection{No merger}

With no labour union, the profits of the firms under no merger are $\pi_{1}=\left(P_{1}-c\right) q_{1}$ and $\pi_{2}=\left(P_{2}-c\right) q_{2}$ respectively.

At stage 3, if the firms compete like Cournot duopolists, given the inverse demand functions in (1), they maximise their profits simultaneously by choosing the respective output. The equilibrium outputs are $q_{1}^{N C}=q_{2}^{N C}=\frac{a-c}{2+\gamma}$, giving the equilibrium profits as $\pi_{1}^{N C}=\pi_{2}^{N C}=\frac{(a-c)^{2}}{(2+\gamma)^{2}}$. The equilibrium consumer surplus and the equilibrium total surplus are $C S^{N C}=\frac{(1+\gamma)(a-c)^{2}}{(2+\gamma)^{2}}$ and $T S^{N C}=C S^{N C}+\pi_{1}^{N C}+\pi_{2}^{N C}=\frac{(3+\gamma)(a-c)^{2}}{(2+\gamma)^{2}}$ respectively.

If the firms compete like Bertrand duopolists, given the direct demand functions in (2), they maximise their profits simultaneously by choosing the respective price. The equilibrium prices are $P_{1}^{N B}=P_{2}^{N B}=\frac{(1-\gamma) a+c}{2-\gamma}$ and the equilibrium outputs are $q_{1}^{N B}=$ $q_{2}^{N B}=\frac{a-c}{(1+\gamma)(2-\gamma)}$, giving the equilibrium profits as $\pi_{1}^{N B}=\pi_{2}^{N B}=\frac{(1-\gamma)(a-c)^{2}}{(1+\gamma)(2-\gamma)^{2}}$. The equilibrium consumer surplus and the equilibrium total surplus under merger are $C S^{N B}=\frac{(a-c)^{2}}{(1+\gamma)(2-\gamma)^{2}}$ and $T S^{N B}=C S^{N B}+\pi_{1}^{N B}+\pi_{2}^{N B}=\frac{(3-2 \gamma)(a-c)^{2}}{(1+\gamma)(2-\gamma)^{2}}$ respectively.

\subsubsection{Merger}

Since the equilibrium wage under the competitive labour market is $c$, the profit of the monopolist merged firm $\mathrm{M}$ is $\pi_{M}=P_{1} q_{1}+P_{2} q_{2}-\beta\left(q_{1}+q_{2}\right) c$. Since there is no difference for a monopolist between the choice of quantity and price for the maximisation of profit, we just consider output choice by firm M. The equilibrium 
outputs will be $q_{1, M}^{N}=q_{2, M}^{N}=\frac{a-\beta c}{2(1+\gamma)}$, giving the equilibrium profit as $\pi_{M}^{N}=\frac{(a-\beta c)^{2}}{2(1+\gamma)}$. The equilibrium consumer surplus and the equilibrium total surplus are $C S_{M}^{N}=\frac{(a-\beta c)^{2}}{4(1+\gamma)}$ and $T S_{M}^{N}=\pi_{M}^{N}+C S_{M}^{N}=\frac{3(a-\beta c)^{2}}{4(1+\gamma)}$ respectively.

\subsubsection{Decision on merger}

We get that $\pi_{M}^{N}>\pi_{1}^{N C}+\pi_{2}^{N C}>\pi_{1}^{N B}+\pi_{2}^{N B}$ indicating that the firms always want to merge. However, the policymaker will allow the merger if it increases total surplus compared to no merger.

Comparing the total surplus under merger to that of under no merger, we get that it is higher under merger if $\beta<\frac{a}{c}-\frac{2 \sqrt{(1+\gamma)(3+\gamma)}(a-c)}{\sqrt{3}(2+\gamma) c} \equiv \beta^{C} \quad\left(\beta<\frac{a}{c}-\frac{2 \sqrt{3-2 \gamma}(a-c)}{\sqrt{3}(2-\gamma) c} \equiv \beta^{B}\right)$ when there is Cournot (Bertrand) competition under no merger.

The following proposition is immediate from the above discussion.

Proposition 1: Consider a competitive labour market. Merger is always profitable for the firms. However, merger increases the total surplus and allowed by the policymaker if $\beta<\frac{a}{c}-\frac{2 \sqrt{(1+\gamma)(3+\gamma)}(a-c)}{\sqrt{3}(2+\gamma) c} \equiv \beta^{C} \quad\left(\beta<\frac{a}{c}-\frac{2 \sqrt{3-2 \gamma}(a-c)}{\sqrt{3}(2-\gamma) c} \equiv \beta^{B}\right)$ when there is Cournot (Bertrand) competition under no merger.

Merger increases concentration in the product market and makes it always profitable for the firms. However, for total surplus, it creates two opposing effects. On one hand, it tends to reduce the total surplus by increasing concentration in the product market. On the other hand, it tends to increase the total surplus due to the synergic 
benefit. If the latter effect is stronger than the former, which happens for relatively lower values of $\beta$, merger increase the total surplus.

The above result suggests that, under a competitive labour market, if the product market is characterised by Cournot (Bertrand) competition under no merger, the policymaker will allow merger for $\beta<\beta^{C} \quad\left(\beta<\beta^{B}\right)$, and the firms will merge. So, in the following section, where we consider a unionised labour market, we will see how the presence of labour unions affect merger formation and the corresponding consumer surplus for $\beta<\beta^{C}\left(\beta<\beta^{B}\right)$ when there is Cournot (Bertrand) competition under no merger.

\subsection{Labour unions}

\subsubsection{No merger}

Given the wages $w_{1}$ and $w_{2}$ set by the labour unions specific to firms 1 and 2 respectively, the profits of the firms under no merger are $\pi_{1}=\left(P_{1}-w_{1}\right) q_{1}$ and $\pi_{2}=$ $\left(P_{2}-w_{2}\right) q_{2}$ respectively.

\subsubsection{Cournot competition}

At stage 3, the firms choose their outputs simultaneously to maximise their respective profits. The equilibrium outputs are $q_{1}=\frac{(2-\gamma) a-2 w_{1}+\gamma w_{2}}{4-\gamma^{2}}$ and $q_{2}=\frac{(2-\gamma) a-2 w_{2}+\gamma w_{1}}{4-\gamma^{2}}$ which are the labour demands faced by the respective labour unions. At stage 2, the labour unions maximise respective utilities simultaneously by setting the wages. The

equilibrium wages are $w_{1}^{L C}=w_{2}^{L C}=\frac{\alpha(2-\gamma) a+2(1-\alpha) c}{2-\alpha \gamma}$, giving the equilibrium outputs 
and profits as $q_{1}^{L C}=q_{2}^{L C}=\frac{2(1-\alpha)(a-c)}{(2+\gamma)(2-\alpha \gamma)}$ and $\pi_{1}^{L C}=\pi_{2}^{L C}=\frac{4(1-\alpha)^{2}(a-c)^{2}}{(2+\gamma)^{2}(2-\alpha \gamma)^{2}}$ respectively. Accordingly, the equilibrium consumer surplus and the equilibrium total surplus are $C S^{L C}=\frac{4(1+\gamma)(1-\alpha)^{2}(a-c)^{2}}{(2+\gamma)^{2}(2-\alpha \gamma)^{2}} \quad$ and $\quad T S^{L C}=C S^{L C}+\pi_{1}^{L C}+\pi_{2}^{L C}+\left(w_{1}^{L C}-c\right) q_{1}^{L C}+\left(w_{2}^{L C}-c\right) q_{2}^{L C}=$ $\frac{4(1-\alpha)\left[3+\gamma+\alpha\left(1-\gamma-\gamma^{2}\right)\right](a-c)^{2}}{(2+\gamma)^{2}(2-\alpha \gamma)^{2}}$ respectively. ${ }^{5}$

\subsubsection{Bertrand competition}

If the firms choose their prices simultaneously to maximise their profits, the equilibrium prices are $P_{1}=\frac{\left(2-\gamma-\gamma^{2}\right) a+2 w_{1}+\gamma w_{2}}{4-\gamma^{2}}$ and $P_{2}=\frac{\left(2-\gamma-\gamma^{2}\right) a+2 w_{2}+\gamma w_{1}}{4-\gamma^{2}}$, giving the equilibrium outputs and the labour demands faced by the corresponding unions as $q_{1}=$ $\frac{\left(2-\gamma-\gamma^{2}\right) a-\left(2-\gamma^{2}\right) w_{1}+\gamma w_{2}}{4-5 \gamma^{2}+\gamma^{4}}$ and $q_{2}=\frac{\left(2-\gamma-\gamma^{2}\right) a-\left(2-\gamma^{2}\right) w_{2}+\gamma w_{1}}{4-5 \gamma^{2}+\gamma^{4}}$. At stage 2, the labour unions maximise their utilities simultaneously by setting respective wages. The equilibrium wages are $w_{1}^{L B}=w_{2}^{L B}=\frac{\alpha\left(2-\gamma-\gamma^{2}\right) a+(1-\alpha)\left(2-\gamma^{2}\right) c}{2-\alpha \gamma-\gamma^{2}}$, giving the equilibrium outputs and profits as $\quad q_{1}^{L B}=q_{2}^{L B}=\frac{(1-\alpha)\left(2-\gamma^{2}\right)(a-c)}{(2-\gamma)(1+\gamma)\left(2-\alpha \gamma-\gamma^{2}\right)} \quad$ and $\quad \pi_{1}^{L B}=\pi_{2}^{L B}=$ $\frac{(1-\gamma)\left(2-\gamma^{2}\right)^{2}(1-\alpha)^{2}(a-c)^{2}}{(1+\gamma)(2-\gamma)^{2}\left(2-\alpha \gamma-\gamma^{2}\right)^{2}}$ respectively. Accordingly, the equilibrium consumer surplus and the equilibrium total surplus are $C S^{L B}=\frac{\left(2-\gamma^{2}\right)^{2}(1-\alpha)^{2}(a-c)^{2}}{(1+\gamma)(2-\gamma)^{2}\left(2-\alpha \gamma-\gamma^{2}\right)^{2}}$ and $T S^{L B}=C S^{L B}+$ $\pi_{1}^{L B}+\pi_{2}^{L B}+\left(w_{1}^{L B}-c\right) q_{1}^{L B}+\left(w_{2}^{L B}-c\right) q_{2}^{L B}=\frac{(1-\alpha)\left(2-\gamma^{2}\right)\left[(3-2 \gamma)\left(2-\gamma^{2}\right)+\alpha\left(2-4 \gamma+\gamma^{2}\right)\right](a-c)^{2}}{(1+\gamma)(2-\gamma)^{2}\left(2-\alpha \gamma-\gamma^{2}\right)^{2}}$ respectively.

\subsubsection{Merger}

Since the labour unions are firm-specific, merger between the firms would also entail

\footnotetext{
${ }^{5}$ As we stated in footnote 4 , we focus on unions' wage bill instead of utility when we calculate total surplus.
} 
merger among the labour unions. Hence, when firms 1 and 2 merge, given the wage $w_{M}$ set by the labour union specific to the merged firm $\mathrm{M}$, the profit of the merged firm is $\pi_{M}=P_{1} q_{1}+P_{2} q_{2}-\beta\left(q_{1}+q_{2}\right) w_{M}$. At stage 3 , firm $\mathrm{M}$ maximises its profit by choosing the output. The equilibrium output is $q_{1, M}^{L}=q_{2, M}^{L}=\frac{a-\beta w_{M}}{2(1+\gamma)}$. Hence, the labour demand faced by the labour union is $L_{M}=\beta\left(q_{1}+q_{2}\right)=\frac{\beta\left(a-\beta w_{M}\right)}{1+\gamma}$. At stage 2, the labour union determines $w_{M}$ to maximise its utility. The equilibrium wage is $w_{M}=\frac{\alpha a}{\beta}+(1-\alpha) c$, giving the equilibrium outputs and profit as $q_{1, M}^{L}=q_{2, M}^{L}=$ $\frac{(1-\alpha)(a-\beta c)}{2(1+\gamma)}$ and $\pi_{M}^{L}=\frac{(1-\alpha)^{2}(a-\beta c)^{2}}{2(1+\gamma)}$ respectively. The equilibrium consumer surplus and the equilibrium total surplus are $C S_{M}^{L}=\frac{(1-\alpha)^{2}(a-\beta c)^{2}}{4(1+\gamma)}$ and $T S_{M}^{L}=C S_{M}^{L}+\pi_{M}^{L}+$ $\left(w_{M}-c\right) \beta\left(q_{1, M}^{L}+q_{2, M}^{L}\right)=\frac{(1-\alpha)(3+\alpha)(a-\beta c)^{2}}{4(1+\gamma)}$ respectively.

\subsubsection{Decision on merger}

We get that $\pi_{M}^{L} \gtreqless \pi_{1}^{L C}+\pi_{2}^{L C}$ for $\beta \lesseqgtr \beta_{1}$, where $\beta_{1}=\frac{a}{c}-\frac{4 \sqrt{1+\gamma}(a-c)}{(2+\gamma)(2-\alpha \gamma) c}$, indicating that, in the presence of unions, the firms would like to merge under Cournot competition if $\beta<\beta_{1}$. However, the policymaker will allow the merger if it increases total surplus compared to no merger. We get that $T S_{M}^{L}>T S^{L C}$ if $\beta<\beta_{1}^{*}$, where $\beta_{1}^{*}=\frac{a}{c}-$ $\frac{4 \sqrt{(1+\gamma)\left[3+\gamma+\alpha\left(1-\gamma-\gamma^{2}\right)\right]}(a-c)}{\sqrt{3+\alpha}(2+\gamma)(2-\alpha \gamma) c}$. Thus, two firms will merge under Cournot competition for $\beta<\operatorname{Min}\left\{\beta_{1}, \beta_{1}^{*}\right\}^{6}$

We also get that $\pi_{M}^{L} \gtreqless \pi_{1}^{L B}+\pi_{2}^{L B}$ for $\beta \lesseqgtr \beta_{2}$, and $T S_{M}^{L}>T S^{L B}$ for $\beta<\beta_{2}^{*}$, where $\quad \beta_{2}=\frac{\mathrm{a}}{\mathrm{c}}-\frac{2\left(2-\gamma^{2}\right) \sqrt{1-\gamma}(\mathrm{a}-\mathrm{c})}{(2-\gamma)\left(2-\alpha \gamma-\gamma^{2}\right) \mathrm{c}} \quad, \quad \beta_{2}^{*}=\frac{a}{c}-\frac{2 \sqrt{\left(2-\gamma^{2}\right)\left[(3-2 \gamma)\left(2-\gamma^{2}\right)+\alpha\left(2-4 \gamma+\gamma^{2}\right)\right]}(a-c)}{\sqrt{3+\alpha}(2-\gamma)\left(2-\alpha \gamma-\gamma^{2}\right) c}$ $\left(<\beta_{2}\right)$, indicating that, in the presence of unions, the firms will merge under Bertrand

\footnotetext{
${ }^{6}$ Note that $\beta_{1} \lesseqgtr \beta_{1}^{*}$ for $\alpha \gtreqless \frac{1}{1+\gamma}$, indicating that there could be situations (when $\beta_{1}<\beta_{1}^{*}$ ) where merger could be socially preferable but not profitable to the firms.
} 
competition for $\beta<\beta_{2}^{*}$.

The following proposition is immediate from the above analysis.

Proposition 2: In the presence of labour unions, merger does not occur under Cournot (Bertrand) competition for $\beta \geq \operatorname{Min}\left\{\beta_{1}, \beta_{1}^{*}\right\} \quad\left(\beta \geq \beta_{2}^{*}\right)$.

On one hand, merger tends to increase the profits of the merged firms by increasing market concentration and creating synergic benefit, but on the other hand, it tends to reduce the profits of the merged firms by increasing wage. For total surplus, merger creates two opposing effects as stated in subsection 2.1.3. Thus, if the synergic benefit is sufficiently stronger, it makes merger profitable and allowed by the policymaker.

\subsection{The impact of labour unions on the consumers}

It is intuitive that if the market structure remains the same under a competitive labour market and a unionised labour market, equilibrium consumer surplus will be higher under the former since the union creates production inefficiency by creating the double marginalisation problem. However, the situation may be different if merger occurs only under a competitive labour market.

We are now in a position to see whether the presence of labour unions can increase consumer surplus by preventing merger compared to the situation where "socially beneficial merger" occurs in the absence of labour unions. In other words, we want to compare consumer surplus under "union and no merger" to that of under "no union and 
socially beneficial merger" for $\operatorname{Min}\left\{\beta_{1}, \beta_{1}^{*}\right\} \leq \beta<\beta^{C}$ (when there is Cournot competition under no merger) and $\beta_{2}^{*} \leq \beta<\beta^{B}$ (when there is Bertrand competition under no merger). ${ }^{7}$

Ignoring the constraint of $\operatorname{Min}\left\{\beta_{1}, \beta_{1}^{*}\right\} \leq \beta<\beta^{C}$ when there is Cournot competition under no merger, comparing consumer surplus under "union and no merger" to that of under "no union and socially beneficial merger" gives that $C S^{L C}>C S_{M}^{N}$ for $\beta>\beta_{C S}^{C}$, where $\beta_{C S}^{C}=\frac{a}{c}-\frac{4(1+\gamma)(1-\alpha)(a-c)}{(2+\gamma)(2-\alpha \gamma) c}$. We also get that in order to make the range $\beta_{C S}^{C}<\beta<\beta^{C} \quad$ not empty, $\quad \alpha<\frac{12+6 \gamma-2 \gamma^{2}-2 \sqrt{3(1+\gamma)(3+\gamma)}(2-\gamma)}{12+12 \gamma-3 \gamma^{2}-\gamma^{3}} \equiv \alpha_{C S}^{C}$ must hold. Under the condition of $\alpha<\alpha_{C S}^{C}$, we have $\beta_{1}>\beta_{1}^{* 8}$ indicating $\operatorname{Min}\left\{\beta_{1}, \beta_{1}^{*}\right\}=\beta_{1}^{*}$. Thus, combining with $\beta_{1}^{*}<\beta^{C}$, we have $C S^{L C}>C S_{M}^{N}$ holds for $\operatorname{Max}\left\{\beta_{C S}^{C}, \beta_{1}^{*}\right\}<$ $\beta<\beta^{C}$ which is not empty if $\alpha<\alpha_{C S}^{C}{ }^{9}$

Similarly, ignoring the constraint of $\beta_{2}^{*} \leq \beta<\beta^{B}$ when there is Bertrand competition under no merger, comparing consumer surplus under "union and no merger" to that of under "no union and socially beneficial merger" gives that $C S^{L B}>C S_{M}^{N}$ for $\beta>\beta_{C S}^{B}$, where $\beta_{C S}^{B}=\frac{a}{c}-\frac{2\left(2-\gamma^{2}\right)(1-\alpha)(a-c)}{(2-\gamma)\left(2-\alpha \gamma-\gamma^{2}\right) c}$. We also get that in order to make the range $\beta_{C S}^{B}<\beta<\beta^{B}$ not empty, $\alpha<\frac{(\sqrt{3}-\sqrt{3-2 \gamma})\left(2-\gamma^{2}\right)}{\sqrt{3}\left(2-\gamma^{2}\right)-\gamma \sqrt{3-2 \gamma}} \equiv \alpha_{C S}^{B}$ must hold. Thus, we have $C S^{L B}>C S_{M}^{N}$ holds for $\operatorname{Max}\left\{\beta_{C S}^{B}, \beta_{2}^{*}\right\}<\beta<\beta^{B}$ which is not empty if $\alpha<$

\footnotetext{
7 We also compared total surplus under "union and no merger" to that of under "no union and socially beneficial merger" for these ranges to see whether the presence of labour unions can increase total surplus. However, the result shows that the presence of labour unions reduces total surplus. As this is consistent with the common belief, we do not report the analysis on the impact of labour unions on total surplus in the paper.

${ }^{8}$ Note that $\alpha_{C S}^{C}<\alpha_{C S}^{C}(\gamma=1)=\frac{4-\sqrt{6}}{5}<\frac{1}{1+\gamma}$.

9 Note that $\beta_{C S}^{C}-\beta_{1}^{*}=\frac{4 \sqrt{1+\gamma}(a-c)}{\sqrt{3+\alpha}(2+\gamma)(2-\alpha \gamma) c}\left[\sqrt{3+\gamma+\alpha\left(1-\gamma-\gamma^{2}\right)}-\sqrt{(1+\gamma)(3+\alpha)}(1-\alpha)\right]$ can be either greater or less than 0 under the constraint of $\alpha<\alpha_{C S}^{C}$.
} 
$\alpha_{C S}^{B} \cdot{ }^{10}$

The following proposition is immediate from the above discussion.

Proposition 3: If the labour union's preference for wage is not high, the presence of labour unions may increase consumer surplus by preventing merger under both Cournot and Bertrand competition in the product market, compared to the situation where socially beneficial merger occurs under a competitive labour market.

\section{Conclusion}

The literature has shown different effects of labour unions in oligopoly markets and some of the effects could well be favourable to consumers due to strategic interactions between unions and firms along with other corporate strategies. The purpose of the present paper is to study the effects of labour unions on the consumers in the presence of a socially preferable merger creating synergic benefits. We consider a duopoly model with differentiated products and analyse the effects of labour unions under both Cournot and Bertrand competitions.

We show that the presence of labour unions may increase consumer surplus by preventing merger compared to the situation where socially beneficial merger occurs under a competitive labour market, and this happens under both Cournot and Bertrand competitions. Thus, our results show concerns on overestimating the adverse effects of

\footnotetext{
$10 \quad$ Note that $\quad \beta_{C S}^{B}-\beta_{2}^{*}=\frac{2 \sqrt{2-\gamma^{2}}(a-c)}{\sqrt{3+\alpha}(2-\gamma)\left(2-\alpha \gamma-\gamma^{2}\right) c}\left[\sqrt{(3-2 \gamma)\left(2-\gamma^{2}\right)+\alpha\left(2-4 \gamma+\gamma^{2}\right)}-\right.$ $\left.\sqrt{\left(2-\gamma^{2}\right)(3+\alpha)}(1-\alpha)\right]$ can be either greater or less than 0 under the constraint of $\alpha<\alpha_{C S}^{B}$.
} 
labour unions on the consumers in imperfectly competitive product markets. It is worth mentioning that although our results do not hold under an industry-wide labour union, they are still significant as firm-specific labour unions and decentralised wage setting are largely predominant in many countries such as UK, North America, and Japan (Flanagan, 1999). 


\section{References}

Buchanan, R.T., 1974, 'Merger waves in British unionism', Industrial Relations Journal, 5: 37-44.

Buchanan, R.T., 1981, 'Mergers in British trade unions 1949-79', Industrial Relations Journal, 12: 40-49.

Cao, J. and A. Mukherjee, 2017, 'Market power of the input supplier, technology transfer and consumer welfare', The Manchester School, 85: 430-449.

Chitayat, G., 1979, Trade union mergers and labour conglomerates, Praeger, New York.

Davidson, C. and A. Mukherjee, 2007, 'Horizontal mergers with free entry', International Journal of Industrial Organization, 25: 157-172.

Fallick, B.C. and K.A. Hassett, 1996, 'Unionization and acquisitions', The Journal of Business, 69: 51-73.

Flanagan R.J., 1999, 'Macroeconomic performance and collective bargaining: an international perspective', Journal of Economic Literature, 37: 1150-1175.

Geroski, P. and K.G. Knight, 1984, 'Corporate merger and collective bargaining in the UK', Industrial Relations Journal, 15: 51-60.

Hirsch, B.T., 1997, 'Unionization and economic performance: evidence on productivity, profits, investment, and growth'. In: Mihlar, F., (Ed.), Unions and right-to-work laws, Vancouver, B. C., The Fraser Institute, 35-70.

Kao, T. and F. Menezes, 2010, 'Welfare enhancing mergers under product differentiation, The Manchester School, 78(4), 290 - 301. 
Lommerud, K.E., O.R. Straume and L. Sørgard, 2005, 'Downstream merger with upstream market power', European Economic Review, 49: 717-743.

Lommerud, K.E., O.R. Straume and L. Sørgard, 2006, 'National versus international mergers in unionized oligopoly', RAND Journal of Economics, 37: 212-233.

López, M.C. and R.A. Naylor, 2004, 'The Cournot-Bertrand profit differential: a reversal result in a differentiated duopoly with wage bargaining', European Economic Review, 48: 681-696.

Mukherjee, A., 2010, 'Product market cooperation, profits and welfare in the presence of labour union', Journal of Industry, Competition and Trade, 10: 151-60.

Mukherjee, A. and L.F.S. Wang, 2013, 'Labour union, entry and consumer welfare', Economics Letters, 120: 603-605.

Mukherjee, A. and L. Zhao, 2016, 'Union structure and the incentive for a cross-border merger', Indian Economic Review, LI, 129-145.

Shrek, J., 2009, What unions do: how labour unions affect jobs and the economy, Backgrounder (Published by the Heritage Foundation) 2275, 1-10.

Straume, O.R., 2002, 'Union collusion and intra-industry trade'. International Journal of Industrial Organization, 20: 631-652.

Straume, O.R., 2003, 'International mergers and trade liberalisation: implications for unionised labour', International Journal of Industrial Organization, 21: 717-735.

Symeonidis, G., 2008, 'Downstream competition, bargaining and welfare', Journal of Economics and Management Strategy, 17: 247-270.

Symeonidis, G., 2010, 'Downstream merger and welfare in a bilateral oligopoly', 
International Journal of Industrial Organization, 28: 230-243. 